\title{
INFORMED CONSENT DOCUMENTS SUBMITTED FOR INITIAL REVIEW: WHAT DO THEY STATE ABOUT COMPENSATION FOR INJURED RESEARCH PARTICIPANTS?
}

\author{
S. B. BAVDEKAR
}

\section{ABSTRACT}

BACKGROUND: Research carries a small but definite risk of injury to participants. However, there is no unanimity amongst the stakeholders regarding the nature and extent of compensation to be provided to an injured participant. AIMS: To determine the extent to which issues related to the provision of free treatment and compensation for research-related injury are addressed in the protocols submitted to Ethics Committees (ECS). SETIING AND DESIGN: Retrospective review of protocols submitted to two ECs in India. MATERIAL AND METHODS: Initial protocols submitted to two ECs during the calendar years 2007 and 2008 were reviewed. Statements related to treatment and compensations for study-related injury were studied for adequacy regarding provisions for free emergency treatment, and free treatment and compensation for researchrelated injury. Presence of special conditions, exclusions, and caveats, if any, were noted. STATISTICAL ANALYSIS USED: The proportion of protocols providing free treatment and compensation for research-related injury was presented as a percentage. RESULTS: The Informed Consent Documents (ICD) of 138 protocols were accessed. These included 115 $(83.33 \%)$ industry-sponsored, 20 (14.49\%) government-sponsored and three $(2.17 \%)$ investigator-initiated projects. Forty-six (33.33\%) intended to provide free treatment for a trial-related injury. Forty-two (30.43\%) projects did not have any policy about providing treatment for a trial-related injury, whereas several others included statements that intended to provide treatment, but with certain restrictions. Thirty-three $(23.91 \%)$ ICDs had statements indicating that there was no provision for compensation and $65(47.10 \%)$ ICDs stated nothing on the issue. CONCLUSION: ICDs submitted for initial review are not in conformity with the provisions for treatment of and compensation for researchrelated injuries enunciated in national guidelines and draft guidelines.

Key words: Biomedical research, consent, compensation and redress

PMID: 19901484

Department of Pediatrics, Seth GS Medical College and KEM Hospital, Mumbai, India

\section{Correspondence:}

Dr. SB Bavdekar,

9, A2 Worli Seaside CHS, Pujari Nagar,

KAG Khan Road, Worli, Mumbai - 400 012, India.

E-mail: sandeep.bavdekar@gmail.com

\section{INTRODUCTION}

Every research study has the potential to cause injury. The Indian Council of Medical Research (ICMR) National Guidelines stipulate that 
injured participants will receive free treatment for the management of study-related injury and would also be compensated for such injuries. ${ }^{[1]}$ These guidelines state that the sponsor should agree, before research begins, in an a priori agreement, to provide compensation for any physical or psychological injury, and delineates a procedure to decide on the issue of providing compensation on a case-by-case basis. The draft guidelines posted on the ICMR website provide additional details on how this has to be ensured. ${ }^{[2]}$ It has been noted that stake-holders involved in research in India, namely, investigators, sponsors, and Ethics Committee members are not always well-informed regarding these issues ${ }^{[3]}$ Hence, we decided to conduct a study to determine the extent to which compensation for study-related injury and for the treatment of such an injury are addressed in initial submissions to Ethics Committees so as to identify the points for training of the stake-holders.

\section{MATERIAL AND METHODS}

The Informed Consent Documents (ICDs) of research projects submitted in 2007 and 2008 were reviewed. These ICDs had been submitted to the Independent Ethics Committee, Mumbai and the Ethics Committee for Research in Human Subjects (ECRHS), an institutional Ethics Committee of Seth GS Medical College and KEM Hospital, Mumbai for initial review. The research trials were classified as being pharmaceutical industrysponsored, government-sponsored, and investigator-initiated. The statements related to compensation for treatment of study-related injury and compensation for study-related injury in these documents were scrutinized for the following:

[A] Management of study-related injury:

- Presence of statement(s) regarding compensation for treatment of studyrelated injury

- Statement(s) for providing free treatment for study-related injury

- Presence of caveats: improper enrollment, investigator negligence, particular arm of the study, whether procedures were to be covered, free treatment only for situations not covered by personal insurance or government programs

[B] Compensation for study-related injury:

- Presence of any statement for providing compensation for study-related injury

- Statement(s) that there would be no such compensation available

- Presence of any caveats or exclusions

The proportion of protocols providing free treatment and compensation for researchrelated injury was presented as percentage. The caveats, exclusions, and conditions, if any, for accessing these were also noted, and their implications for the study participants examined.

\section{RESULTS}

The ICDs of 138 protocols were accessed including 115 (83.33\%) industry-sponsored, $20(14.49 \%)$ government-sponsored, and three $(2.17 \%)$ investigator-initiated projects. As stated in Table 1, only 46 (33.33\%) gave an unequivocal statement that free treatment would be provided in case of a trial-related injury. As many as $42(30.43 \%)$ projects did not state anything about providing treatment for a trialrelated injury, whereas several others included statements that indicated certain restrictions. 
Table 1: Information in Informed Consent Documents related to management of research-related injury and compensation for trial related injury

\begin{tabular}{|c|c|c|c|c|c|c|c|}
\hline \multicolumn{8}{|c|}{ Management of Injury } \\
\hline $\begin{array}{l}\text { Nothing } \\
\text { mentioned }\end{array}$ & $\begin{array}{l}\text { Free } \\
\text { treatment }\end{array}$ & $\begin{array}{l}\text { Free treatment } \\
\text { if not covered } \\
\text { by personal } \\
\text { insurance }\end{array}$ & $\begin{array}{l}\text { Free treatment if } \\
\text { not covered } \\
\text { by govt. } \\
\text { programs }\end{array}$ & $\begin{array}{l}\text { Treatment will } \\
\text { be provided }\end{array}$ & $\begin{array}{l}\text { As per } \\
\text { insurance }\end{array}$ & $\begin{array}{l}\text { Only for } \\
\text { study drug }\end{array}$ & $\begin{array}{l}\text { If properly } \\
\text { performed }\end{array}$ \\
\hline 42 & 46 & 29 & 27 & 4 & 3 & 3 & 6 \\
\hline \multicolumn{8}{|c|}{ Compensation for trial-related injury } \\
\hline $\begin{array}{l}\text { Nothing } \\
\text { mentioned }\end{array}$ & $\begin{array}{l}\text { No provision for } \\
\text { compensation }\end{array}$ & $\begin{array}{l}\text { Trial } \\
\text { Insurance } \\
\text { taken }\end{array}$ & $\begin{array}{l}\text { Trial insured for } \\
\text { injury } \\
\text { compensation }\end{array}$ & $\begin{array}{l}\text { For trial } \\
\text { drug arm }\end{array}$ & $\begin{array}{l}\text { Compensation } \\
\text { available }\end{array}$ & $\begin{array}{l}\text { As per ABPI } \\
\text { Guidelines }\end{array}$ & \\
\hline 65 & 33 & 9 & 1 & 1 & 24 & 2 & \\
\hline
\end{tabular}

*Injury-related issues were not applicable for one project as it involved study on stored samples

Where compensation for trial-related injury was concerned, $33(23.91 \%)$ had statements clearly indicating that there would be no provision for compensation whereas 65 (47.10\%) ICDs stated nothing on the issue. Several ICDs imposed caveats while providing treatment for injury and hence, statements such as, 'costs of injury not covered by personal insurance or government program would be reimbursed' appeared in the reviewed documents. Ambiguous statements such as, 'treatment will be provided in case of trial-related injury,' or 'treatment will be provided as per insurance' also appeared in the documents. The first statement does not state who will bear the cost of treatment and the latter does not provide any details. Restrictions such as providing treatment and/or compensation for trial-related injury only to participants in the active drug arm or only if the study would be done as per protocol were also noted. There were ICDs that averred that free treatment or compensation would be provided only if the study would be properly conducted, conducted as per protocol, if the investigator(s) had not erred, or if there had been no negligence on the part of investigating team.

Tables 2 and 3 provide salient examples of statements that do not provide complete information or put undue restrictions on participants' rights related to the treatment of and compensation for trial-related injury. It was also observed that the issues of treatment and compensation were not handled separately. For example, one ICD had a statement that the trial was insured for trial-related injury. It was not clear from the statement whether this would make eligible participants receive free treatment in case of trial-related injury or if they would be compensated for such an injury, or both.

\section{DISCUSSION}

The study shows that a large proportion of ICDs submitted with protocols for initial review to Ethics Committees do not conform to National Guidelines, nor do they adequately protect the interests of the participants. This could partly be due to ignorance about these issues among sponsors and investigators. This, however, puts onerous responsibilities on the shoulders of the members of Ethics Committees. They need to be aware of the implications of the way the twin issues of providing treatment and providing compensation are currently being handled [Tables 2 and 3]. Several documents had statements that indicated what a sponsor 
Table 2: Examples of Statements related to payments for the treatment of study-related injury and their implications

\begin{abstract}
Statement
"While providing appropriate medical treatment for study-related injury, there is no commitment to provide you with free medical treatment for such an injury or illness unless the study sponsor, at its discretion approves payment for such medical treatment, over and above any amounts paid by your health insurance."

"Compensation for the treatment(s) will be made available to the subject in the event of a trial-related injury. The sponsor will financially cover any injury caused to you related to XYZ-1234 during the study period."
\end{abstract}

"If you follow the directions of the doctors and you are physically injured because of any substance or procedure properly given to you under the plan of this study, the medical expenses for the treatment of that injury would be borne by the sponsor."

"What about insurance and compensation?

You will not be paid any kind of compensation in cash. But, in case of any study-related injury; you will be treated for that injury by the insurance policy done by sponsor."

"I understand that xyz is a fairly safe drug. It may cause rash, photosensitivity reactions, peeling of the skin (exfoliative dermatitis) or severe drug reaction called Stevens-Johnson syndrome. I will have to report to the doctor, if I feel discomfort on taking that medicine. The doctor will take appropriate measures to see that my health is safeguarded."

"The sponsor will pay for the medical costs if it has been determined that your child qualifies for enrollment, if you have followed instructions and the bad effects came due to your child's participation in the study."

"Reimbursement shall be made by the funder for the study, for reasonable and necessary medical expenses incurred by a study participant as a direct result of the treatment of adverse reactions from the drugs used in the study in accordance with the protocol, provided such expenses are not covered by participant's medical or hospital insurance coverage, and are in no way attributable to the negligence or misconduct of any agent or employee of XYZ Hospital."

"What if something goes wrong?

During the course of the trial, if anything goes wrong or you experience any serious medical event, please let your doctor know immediately. You will be provided with utmost medical care including hospital admission. If you are harmed due to someone's negligence, then you may have grounds for legal action."

"The IUD may rarely cause perforation of uterus. If you have any such complaint during use, you will be provided treatment/counseling. However, if there is any life-threatening medical condition, you will report to the hospital and will be managed as per normal hospital practices. There is no monetary compensation for enrollment, follow-up or in the event of any side-effect."
Implications

- No free treatment even when the injury is study-related.

- Discretion rests solely with the sponsor.

- Participants in control arm and injuries related to study-procedures not included in compensation.

- No payment for treatment of injury if substance or procedure not given/done properly by the investigator(s).

- Details of insurance policy not revealed to the participant. Exclusions in the policy could harm participants' interests.

- No mention of free treatment or whether expenses on treatment of study-related injury would be reimbursed.

- No payment for treatment related injury, if there is wrongful enrollment by the investigator.

- Too many caveats

- Injury related to study procedures (other than administration of drugs) not covered.

- Who will bear the cost of treatment has not been stated.

- Indicates that no compensation will be provided if the investigator or his team has erred. The participant has to take recourse to costly and time-consuming legal processes.

- 'Normal hospital practices' not explained.

- No compensation for study-related injury. would do. For example, it was stated that no compensation would be provided if injury occurred due to the investigator or his/her team failing to adhere to the protocol. This is unfair to the research participant, especially as the sponsor, and not the participant, selects the investigator. Under such circumstances, surely the sponsor could provide compensation by invoking the principle of vicarious responsibility.
If the sponsor were unwilling, the participants cannot be left to fend for themselves and there should be some mechanism for providing compensation and free treatment for injury, either through the investigator or his/her institution. It is noteworthy that of the 129 policies of 102 academic medical centers in the USA, $51 \%$ made no provision for providing free care and $8 \%$ provided only free emergency or 
Table 3: Statements related to compensation for study-related injury and their implications

\begin{tabular}{|c|c|}
\hline Statement & Implications \\
\hline $\begin{array}{l}\text { "The 'sponsor' will reimburse the cost of extra unanticipated tests, treat- } \\
\text { ments, hospitalizations of patients required as a result of adverse events } \\
\text { which the 'sponsor' determines with reasonable medical certainty, to } \\
\text { have resulted from substances dispensed or administered properly and } \\
\text { in accordance with study protocol." }\end{array}$ & $\begin{array}{l}\text { - The research participant will need to spend on tests } \\
\text { without any certainty of being reimbursed of those } \\
\text { expenses. } \\
\text { - No reimbursement even if injury has occurred due } \\
\text { to errors committed by investigation team in adminis- } \\
\text { tering substances or in following the protocol }\end{array}$ \\
\hline $\begin{array}{l}\text { "The 'sponsor' has taken out an insurance policy to cover compensa- } \\
\text { tion for any personal injury resulting from the participation in this study, } \\
\text { provided such injury is not due to fault or negligence." }\end{array}$ & $\begin{array}{l}\text { - It is not clear if the participant would be eligible for } \\
\text { compensation if the investigator has committed fault } \\
\text { or negligence. }\end{array}$ \\
\hline
\end{tabular}

immediate care. As many as $19 \%$ of the policies did not provide publicly accessible information in this regard. ${ }^{[5]}$

The data was collected from only two ECs situated in Mumbai. It may be argued that this may not be representative of the situation in the whole country. It may be clarified here that the ECRHS received proposals from several pharmaceutical companies and that the Independent EC received research proposals from several other cities and towns in India. The findings of the study provide an insight into the existing lacunae and have helped identify the training needs. The policy regarding ethical issues is generally enunciated in the Ethics section of the Protocol. However, this protocol is not generally accessible to prospective participants, and in any case, the ICD is expected to reflect and clarify the policy stated in the Protocol. Hence, these documents were studied in preference to the Protocol.

\section{Table 4: Providing adequate protection to research participants in case of injury: What can Ethics Committees do?}

- Organize training programs to discuss the issue of providing treatment and compensation for research-related injury with investigators and sponsors: Current thinking and guidelines.

- Have a well-thought out policy on what the minimal expectations would be regarding providing treatment and compensation when a research participant suffers trial-related injury.

- Have a mechanism in place to handle appeals and disputes and to decide on the quantum of compensation.

- Provide a template for ICD:

Clearly differentiate between compensation for participation, treatment for trial-related injury, and compensation for trial-related injury.

Treatment for trial-related injury: Have an arrangement to provide emergency treatment free of cost, provide free treatment or reimburse expenses incurred on treatment of trial-related injury, delineate steps that the participant should take if anything untoward occurs, do away with caveats related to using personal insurance or government program(s).

Do away with restrictions such as treatment/compensation being available only for the trial drug arm, only for substances administered (not for trial-related procedures), only if the study is properly conducted as per protocol, and only if eligibility has been properly assessed.

In case of error/negligence on part of the investigator, there should be some mechanism for providing free treatment and compensation for a trial-related injury, if the sponsor is unwilling to do so.

- Train EC members in sifting ICDs for statements providing inadequate protection. 
The EC members need to be very vigilant and ensure that these statements are: i) in conformity with the letter and spirit of national and international guidelines, ii) are not ambivalent or ambiguous, and iii) fully protect the interests of research participants. In addition, the ECs should take the initiative to inform and educate investigators and stakeholders from industry about current opinions and expectations. Some broad suggestions are provided in Table 4 that would help investigators and sponsors submit ICDs that provide adequate protection to participants who may suffer from trial-related injury.

\section{ACKNOWLEDGMENT}

The author also expresses his gratitude to $\mathrm{Dr} M L$ Kothari, Chairperson, Ethics Committee for Research on Human Subjects and Dr RD Lele, Chairperson, Independent Ethics Committee, Mumbai for permitting the author to carry out the study and put these results in the public domain. The author is also grateful to the staff of these Ethics Committees for extending cooperation in accessing the documents.

\section{REFERENCES}

1. Indian Council of Medical Research. Ethical Guidelines for Biomedical Research on Human Participants. Available from: http://www.icmr.nic. in/ethical_guidelines.pdf [last accessed on 2009 Oct 27]

2. Draft Guidelines for Compensation to Participants for Research Related injury in India. Draft V 14.0 Date: $14^{\text {th }}$ November 2008. Available from: http:// www.icmr.nic.in/icmrnews/compensation_guide. pdf [last accessed on 2009 Feb 19]

3. Thatte UM, Kulkarni-Munshi R, Kalekar SA. Review of policies for injuries to research participants in India. J Med Ethics 2009;35:133-9.

4. Thatte UM, Bavdekar SB. Clinical Research in India: Great Expectations? J Postgrad Med 2008;54:318-23

5. Steinbrook R. Compensation for injured research participant. N Engl J Med 2006;354:1871-3.

Source of Support: Nil. Conflict of Interest: The author is a member institutional and independent ethics committees.

\section{Author Help: Reference checking facility}

The manuscript system (w ww.journalonw eb.com) allows the authors to check and verify the accuracy and style of references. The tool checks the references with PubM ed as per a predefined style. Authors are encouraged to use this facility, before submitting articles to the journal.

- The style as well as bibliographic elements should be $100 \%$ accurate, to help get the references verified from the system. Even a single spelling error or addition of issue number/month of publication will lead to an error when verifying the reference.

- $\quad$ Example of a correct style Sheahan P, O'leary G, Lee G, Fitzgibbon J . Cystic cervical metastases: Incidence and diagnosis using fine needle aspiration biopsy. Otolaryngol Head Neck Surg 2002;127:294-8.

- $\quad$ Only the references from journals indexed in PubM ed will be checked.

- $\quad$ Enter each reference in new line, without a serial number.

- Add up to a maximum of 15 references at a time.

- If the reference is correct for its bibliographic elements and punctuations, it will be shown as CORRECT and a link to the correct article in PubM ed will be given.

- If any of the bibliographic elements are missing, incorrect or extra (such as issue number), it will be show $n$ as INCORRECT and link to possible articles in PubM ed will be given. 